\title{
Correction to: Impact of Hurricane Harvey on Galveston Bay Saltmarsh Nekton Communities
}

\author{
Jenny W. Oakley ${ }^{1} \cdot$ George J. Guillen ${ }^{1}$
}

(C) The Author(s) 2019

Published online: 14 August 2019

Correction to: Estuaries and Coasts

https://doi.org/10.1007/s12237-019-00581-7

In the original article the alignment of the columns in Table 1 was wrong. Following is the corrected table. The original article has also been corrected:

Open Access This article is distributed under the terms of the Creative Commons Attribution 4.0 International License (http:// creativecommons.org/licenses/by/4.0/), which permits unrestricted use, distribution, and reproduction in any medium, provided you give appropriate credit to the original author(s) and the source, provide a link to the Creative Commons license, and indicate if changes were made.

The online version of the original article can be found at https://doi.org/ 10.1007/s12237-019-00581-7

Jenny W. Oakley

oakley@uhcl.edu

1 Environmental Institute of Houston, University of Houston-Clear Lake, 2700 Bay Area Blvd, Houston, TX 77058, USA 


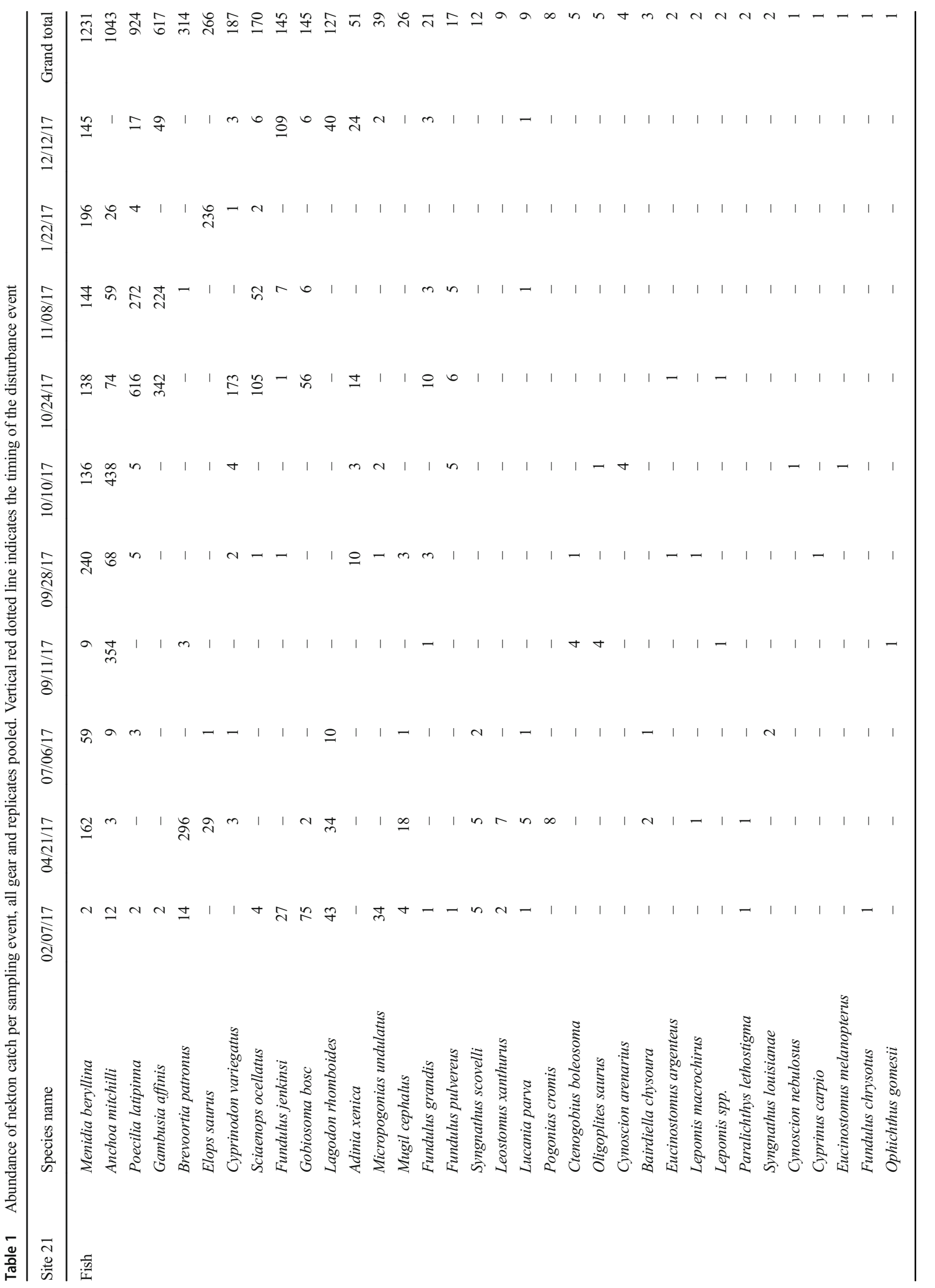




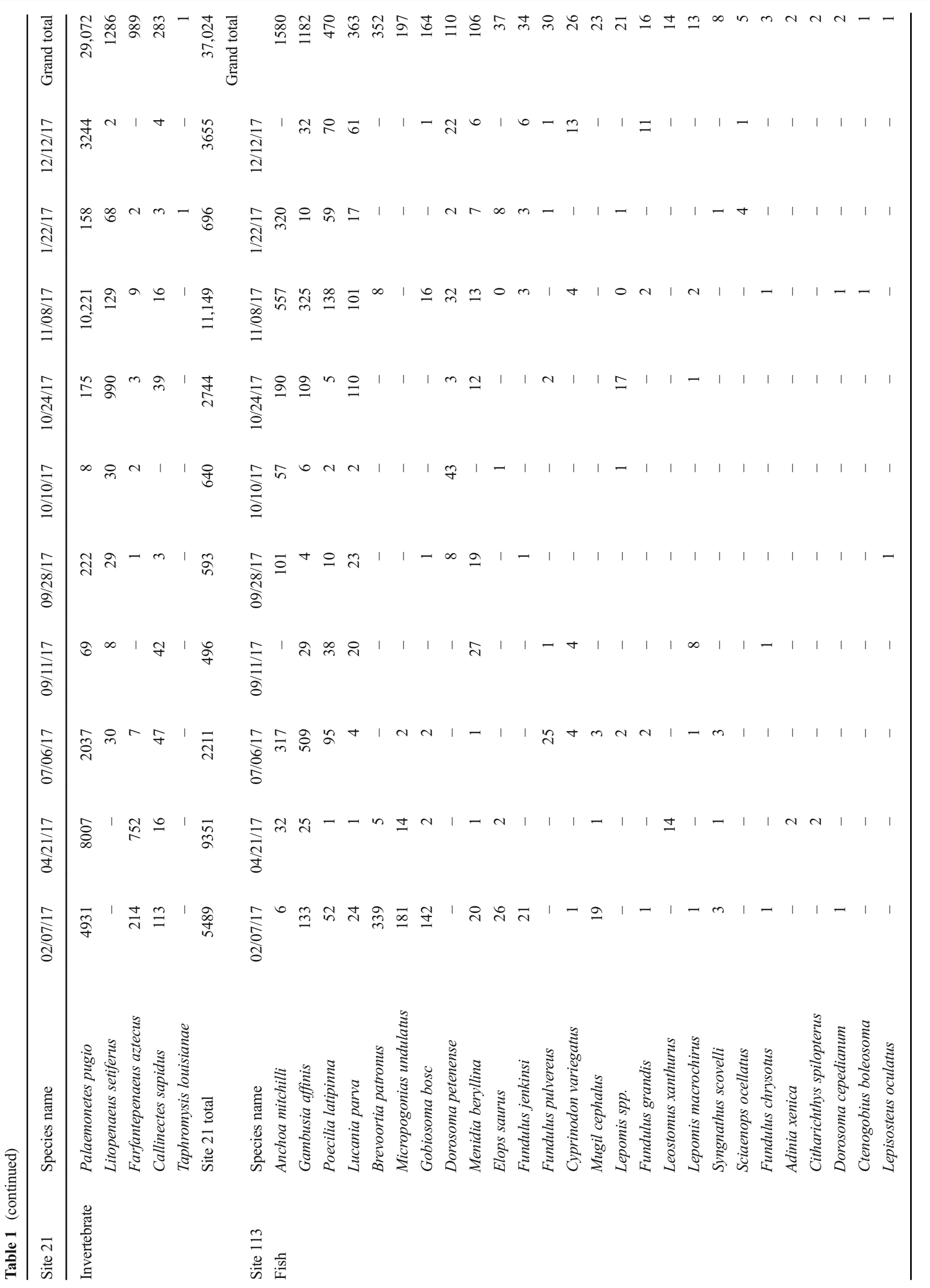




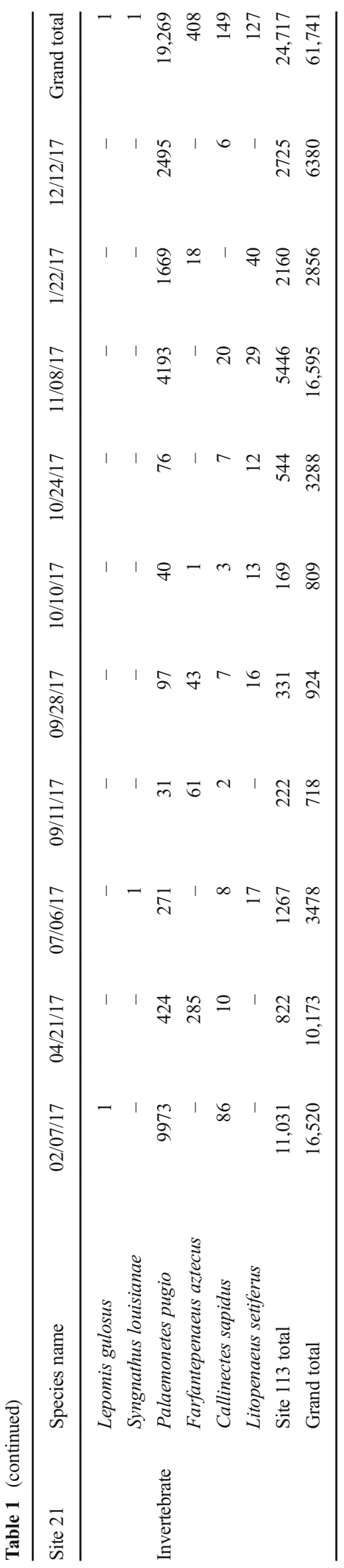

